\title{
Impact of collaborative innovation on green total factor productivity in Yangtze River Economic Belt: Analysis based on endogenous spatial-temporal weight matrix
}

lei Wu ( $\nabla$ wulei18@cug.edu.cn )

China University of Geosciences https://orcid.org/0000-0001-8761-2867

Xiaoyan Jia

China University of Geosciences School of Economics and Management Jie Lv

China University of Geosciences School of Economics and Management Li Gao

China University of Geosciences School of Economics and Management

\section{Research Article}

Keywords: Green total factor productivity, Spatial Durbin model, Collaborative innovation, Environmental protection

Posted Date: June 22nd, 2021

DOI: https://doi.org/10.21203/rs.3.rs-406999/v1

License: (9) This work is licensed under a Creative Commons Attribution 4.0 International License.

Read Full License 


\title{
1 Impact of collaborative innovation on green total factor
}

2 productivity in Yangtze River Economic Belt: Analysis based on

3 endogenous spatial-temporal weight matrix

\author{
Lei $\mathrm{Wu}^{1} \cdot$ Xiaoyan $\mathrm{Jia}^{1} \cdot \mathrm{Jie}^{1} \mathrm{Lv}^{1} \cdot \mathrm{Li} \mathrm{Gao}^{1}$
}

6 Abstract

7 Technological innovation can promote high-quality economic growth. This paper discusses the promotion of green 8 total factor productivity from the perspective of collaborative innovation in the Yangtze River Economic Belt. 9 Firstly, the evaluation index system of collaborative innovation level is constructed from two aspects of 10 collaborative innovation elements and collaborative innovation environment. Then the entropy method is used to 11 measure its development level. The results show that the collaborative innovation level of provinces in the Yangtze 12 River Economic Belt presents an increasing trend year by year. Meanwhile, there are regional differences, which is 13 characterized by 'high in the middle reaches, middle in the downstream and low in the upstream' Secondly, the 14 SDM model based on endogenous spatio-temporal weight matrix is constructed to analyze the influencing factors 15 of green total factor productivity. The results show that collaborative innovation in the Yangtze River Economic 16 Belt has significant negative impact on green total factor productivity in terms of spatial interaction and fiscal 17 expenditure also has a negative impact. The spatial interaction between environmental protection and opening up 18 has a significant positive impact on green total factor productivity. However, the spatial interaction between 19 industrial structure and human capital on green total factor productivity is not obvious. Finally, this paper puts 20 forward some policy suggestions to improve green total factor productivity.

\section{Keywords:}

22 Green total factor productivity; Spatial Durbin model; Collaborative innovation; Environmental protection

\section{Highlights :}

- Construct a mathematical model of collaborative innovation and green total factor productivity.

- Constructed a collaborative innovation level evaluation index system from two aspects called collaborative innovation elements and collaborative innovation environment.

- Establish an SDM model based on the endogenous time-space weight matrix to empirically analyze the

28 factors affecting green. total factor productivity.

\section{Corresponding author:}




\section{The affiliation and address:}

321 School of Economics and Management, China University of Geosciences, Wuhan, 430074, 33 China

\section{Introduction}

At present, China's economy has shifted from high-speed growth stage to high-quality development stage. It

37 is necessary to change the development mode, transform the growth momentum and accelerate the development of 38 green economy. Therefore, Chinese government proposes to implement the innovation-driven development 39 strategy, emphasizing that scientific and technological innovation is a strategic support for improving social 40 productivity and comprehensive national strength. In the meantime, it is necessary to focus on promoting scientific 41 and technological innovation. Collaborative innovation is a new paradigm of today's scientific and technological 42 innovation(Chen and Yang 2012), which is the driving force to promote regional economic development (Liu and 43 Chen 2020). Therefore, whether collaborative innovation promotes the improvement of green total factor 44 productivity is crucially significant for China to accelerate green development.

The Yangtze River Economic Belt is a national strategic development area in China, covering 11 provinces 46 and cities, including Shanghai, Jiangsu, Zhejiang, Anhui, Jiangxi, Hubei, Hunan, Chongqing, Sichuan, Yunnan and Guizhou. The details are shown in Figure 1 below. 


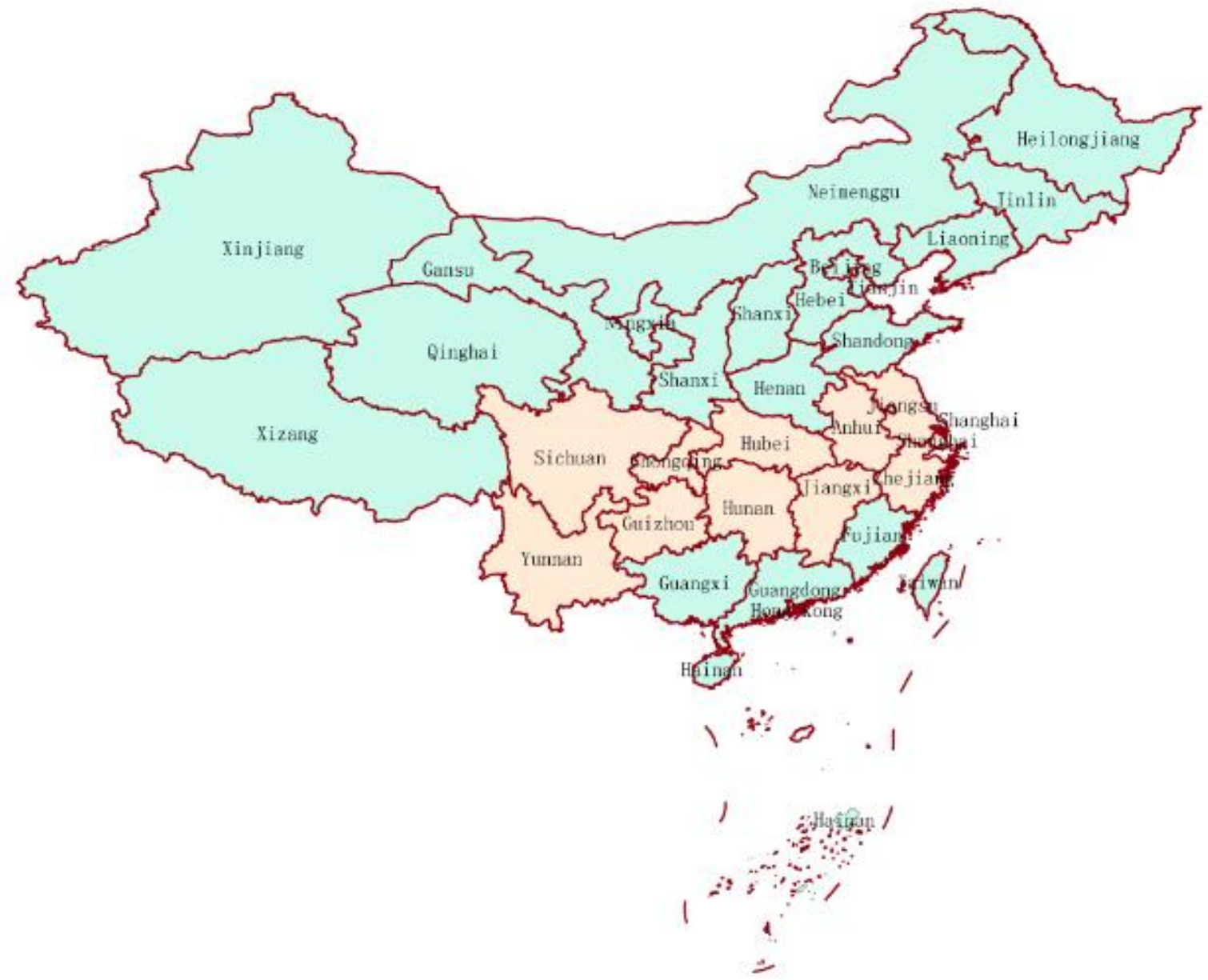

Fig 1. Map of the Yangtze River Economic Belt

The belt area is about 2.052300 square kilometers, accounting for $21.4 \%$ of the country and its population and GDP are more than $40 \%$ of the country. It is rich in science and education resources. For example, the number of ordinary colleges and universities accounts for $43 \%$ of the country, R\&D expenditure accounts for $46.7 \%$ of the country and effective invention patents account for more than $40 \%$ of the country. Otherwise, there are 2 comprehensive national science centers, 9 national independent innovation demonstration zones, 90 national hightech zones, 161 national key laboratories and 667 enterprise technology centers along the Yangtze River. Therefore, relying on the advantages of regional talent and intelligence intensive, accelerating the cross-regional collaborative innovation of the Yangtze River Economic Belt, strengthening environmental protection and planning green development are the keys to the sustainable development of the Yangtze River Economic Belt. Yangtze River Economic Belt (2020)》, the average input index of scientific and technological innovation in the

61 Yangtze River Economic Belt is 0.12 and the average driving force index of scientific and technological 
innovation is 0.14 , which both are at a low level. So, in the context of green development concept, what is the development of collaborative innovation in the Yangtze River Economic Belt? Does it really promote regional green total factor productivity? On the basis of considering the spatial spillover effect of collaborative innovation, this paper discusses the relationship between collaborative innovation and green total factor productivity in the Yangtze River Economic Belt. The conclusion will provide scientific reference for the Yangtze River Economic Belt to promote green total factor productivity through collaborative innovation.

\section{Literature review}

Collaborative innovation was first proposed by Peter Gloor of the Massachusetts Institute of Technology (MIT). It refers to a network of self-motivated people who share a collective vision and achieve common goals through network communication and cooperation (Gloor 2006). Lee and Park pointed out that collaborative innovation is mainly through R\&D cooperation and can enhance the agglomeration of knowledge (Lee and Park 2006). Belderbos et al. (2004) believed that the most effective way to achieve innovation is to cooperate with research institutions. Scholars further measure the degree and performance of collaborative innovation. For example, Persaud defines the evaluation index system of collaborative innovation ability from four aspects, strategic $\mathrm{R} \& \mathrm{D}$, management and operation, knowledge management and innovation degree, and then promotes the measurement of collaborative innovation degree theoretically (Persaud 2005). Leydesdorff and Fritsch use information flow in innovation subsystem as a measure of collaborative innovation (Leydesdorff and Fritsch 2006).

Collaborative innovation can integrate innovation elements and make innovation resources accessible within the region, thereby enhancing the level of total factor productivity and promoting regional economic growth $(\mathrm{Hu}$ et al. 2019). In view of the spatial correlation of collaborative innovation, on the one hand, some scholars explore the relationship between collaborative innovation and economic growth from a spatial perspective. Using spatial econometric model, Shi et al. (2019)Shi Rong found that the synergistic effect of financial innovation and financial agglomeration significantly enhanced the positive effect of financial market on economy. Hu et al. (2019) use spatial lag model research shows that collaborative innovation in Yangtze River Delta urban agglomeration has significant spatial spillover effect, which can promote regional economic growth through direct effect, indirect effect and total effect. Hao and Yin (2019) established GMM and spatial panel Durbin model to study China's 
91 spatial differences. It is found that the investment in science and technology collaborative innovation has a positive 92 impact on economic growth in the current period and local. By also using the spatial panel econometric model, LV 93 et al.(2017). found that the spatial linkage of innovation resource synergy has a significant promoting effect on 94 regional economic growth. On the other hand, some scholars explored their relationship from other perspectives. 95 For instance, Zhou and Li (2017) expounded the dynamic co-evolution of institutional innovation and technological innovation to promote economic growth through a government-enterprise game model. Liu et al.

97 (2017) believes that intra-regional synergy and inter-regional synergy of regional innovation networks are significantly positively correlated with industrial economic growth. From the micro level, Ren and Gan (2016) believe that the collaborative innovation system formed by business model innovation will promote the quality of macroeconomic growth.

However, relevant research shows that the promoting effect of collaborative innovation on economic growth is not obvious. For example, Dai et al. (2019) analyzed the industry-university-research collaborative innovation in

103 Liaoning coastal economic belt from the perspectives of input and output believing that it did not make 104 outstanding contributions to the economy. Wang and Gao (2018) used the algorithm of C-D production function 105 and Solow residual value to calculate the effect of collaborative innovation of science and technology progress on 106 the growth of construction industry was very insignificant. Zhong and Liu (2018) used the extended Cobb-Douglas 107 production function to empirically show that innovative entrepreneurship has no significant impact on China's 108 economic growth. Through co-integration regression and ECM model regression analysis, Lv and Kan (2017) 109 believed that industry-university-research collaborative innovation has little effect on promoting economic growth 110 in Jiangxi in the short term.

111 Technological innovation plays a vital role not only in the development of human society but also in 112 economic development (Adak 2015; Ganda 2019).On the one hand, some scholars believed that technological 113 innovation helps to improve economic development and total factor productivity. Given that green technology 114 innovation is an important part of technology innovation (Chen et al. 2019; Deng et al. 2019), so (Fan and Sun 115 2020) believed that green technology innovation is the main driving force for improving the development of green 116 economy. Meanwhile, He (2015) believed that green technology innovation can effectively improve the total 117 factor productivity of the industry. On the other hand, some scholars believed that the relationship between 118 technological innovation and the improvement of green total factor productivity is not clear. For example, Jin et al. 119 (2019) believe that there is no significant impact between technological innovation and the green total factor 120 productivity of industrial water resources. Wang et al. (2020) believed that there is regional heterogeneity in the 
121 relationship between technological innovation and green total factor productivity. The improvement of

122 technological innovation in the western region of China helps to improve the green total factor productivity, while

123 the eastern and central regions of China have the opposite conclusion. In addition, technological innovation has a

124 significant positive impact on the local green total factor productivity and has a significant negative impact on the

125 green total factor productivity in the surrounding areas.

126 In summary, although the conclusions of the impact of collaborative innovation on economic growth in the 127 above studies are not the same, they all verify the existence of the impact of collaborative innovation on total 128 factor productivity. And then the impact is uncertain. At the same time, most of the previous studies only examined 129 the relationship between collaborative innovation and economic growth without taking into account the ecological 130 and environmental effects of economic growth. That is to say, there was no further in-depth analysis of the impact 131 of collaborative innovation on green economic growth and little literature specifically conducts similar studies on 132 the Yangtze River Economic Belt. The main contributions of this paper are as follows: firstly, a mathematical 133 model is established to analyze the impact mechanism of regional collaborative innovation on green total factor 134 productivity. Secondly, this paper constructs an index system to measure regional collaborative innovation, 135 specifically analyzing the level of collaborative innovation in the Yangtze River Economic Belt and further 136 exploring its spatial dynamic evolution characteristics. Thirdly, the spatial economic matrix is established to 137 explore the impact of collaborative innovation on green total factor productivity in the Yangtze River Economic 138 Belt from the perspective of spatial spillover effect. Therefore, this study has important guiding significance for 139 accelerating the high-quality development of China's green economy.

\section{Theoretical model analysis}

142 Based on the production function, this paper constructs a spatial expansion model of collaborative innovation

143 and analyzes how collaborative innovation affects regional green total factor productivity growth through

144 provincial spatial spillover mechanism. Total factor productivity refers to the ratio of the total output of a system to 145 the input of various production factors. Green total factor productivity is the efficiency of resource development 146 and utilization based on total factor productivity, which takes energy consumption and environmental costs into 147 account. Referring to Zhu Wentao' s research on green total factor productivity calculation (Zhu et al. 2019), the 148 green total factor productivity corresponding to the province $\mathrm{i}$ is expressed as : 


$$
\operatorname{GTFP}_{i, t}=\frac{Y_{i, t}}{L_{i, t}^{\alpha} K_{i, t}^{\beta}}
$$

Among them, $G T F P_{i, t}$ is the corresponding green total factor productivity of provinces $\mathrm{i}$ in years $\mathrm{t} ; Y_{i, t}$ is the corresponding total output; $L_{i, t}$ is the corresponding labor input, $K_{i, t}$ is the corresponding capital input; $\alpha$ and $\beta$ are the share of labor and capital in the input respectively. expressed as (Broda et al. 2006) :

$$
Y_{i, t}=\left(A_{i, t} L_{i, t}\right)^{\alpha}\left[\int_{0}^{Q_{i, t}} P_{i, t}(\tau)^{\tau} d v\right]^{\beta / \tau}
$$
alternatives are. $P_{i, t}$ is other production factors. At the same time, this paper considers that other production factors have the same price and proportion of inputs, the total output can be further expressed as :

$$
Y_{i, t}=\left(A_{i, t} L_{i, t}\right)^{\alpha} Q_{i, t}{ }^{\beta} / \tau P_{i, t}^{\beta}
$$
conditions, the $i$ capital stock of the province can be expressed as :

$$
K_{i, t}=Q_{i, t} P_{i, t}
$$

160 The total output of province i can ultimately be expressed as :

$$
Y_{i, t}=\left(A_{i, t} L_{i, t}\right)^{\alpha} Q_{i, t}\left(\left({ }^{1-\tau} / \tau\right) \beta\right) K_{i, t}^{\beta}
$$

161 Then the corresponding Eq. (1) can be transformed into :

$$
\operatorname{GTFP}_{i, t}=A_{i, t}{ }^{\alpha} Q_{i, t}((1-\tau / \tau) \beta)
$$



technological innovation of other production factor combinations represented by $A_{i, t}{ }^{\alpha}$ and diversification of other production factors represented by $Q_{i, t}\left({ }^{(1-\tau / \tau) \beta)}\right.$. as :

$$
A_{i, t}{ }^{\alpha}=\xi \prod_{j=1}^{n}\left(\frac{T_{j, t}}{G T F P_{i, t}}\right)^{\gamma \omega_{i, j}}
$$

Where $T_{j, t}$ represents the geometric average of technical level of all provinces; $\gamma$ is defined as the absolute value of the level of technological gap valued in $[0,+\infty]$, which indicates the technological gap between province $\mathrm{j}$ and province i. If $\gamma$ tends to 0 , it indicates that the technological gap is small; $\omega_{i, j}$ represents the economic matrix. When $i=j, \omega_{i, j}=0$; when $i=j, \sum_{\mathrm{j} \neq \mathrm{i}}^{\mathrm{n}} \omega_{i, j}=1$.

Since technological innovation results need to be transformed into production technology to improve the actual production efficiency. However, the transformation ability of innovation achievements will be affected by the technological level gap in different regions. If the technological level of the region is higher, the ability to transform innovative achievements is stronger. Assuming that the technological level of province $\mathrm{i}$ is higher than that of province $\mathrm{j}$, the corresponding transformation of innovation achievements of each province is specifically expressed as :

$$
\begin{gathered}
A T_{i, t}=\rho_{i} C I_{i, t}{ }^{\gamma} \\
A T_{j, t}=\rho_{j} C I_{j, t}{ }^{-\gamma}
\end{gathered}
$$

Among them, $C I_{i, t}$ and $C I_{j, t}$ denote the level of collaborative innovation corresponding to the t-year of $\mathrm{i}$ and $\mathrm{j}$ provinces respectively; AT denotes the level of transformation of collaborative innovation achievements. $\rho_{i}$ and $\rho_{j}$ represent other influencing factors. 
elastic coefficient of innovation results. :

$$
Q_{i, t}((1-\tau / \tau) \beta)=A T_{i . t}^{\zeta} \prod_{j=1}^{n}\left(A T_{j . t}^{\zeta}\right)^{\gamma \omega_{i, j}}
$$

182

Substituting Eq. (7) (8)(9)(10) into Eq. (6), we can get :

$$
\operatorname{GTFP}_{i, t}=\xi \prod_{j=1}^{n}\left(\frac{T_{j, t}}{\operatorname{GTFP} P_{i, t}}\right)^{\gamma \omega_{i, j}} A T_{i . t}^{\zeta} \prod_{j=1}^{n}\left(A T_{j . t}^{\zeta}\right)^{\gamma \omega_{i, j}}
$$

183

Taking logarithms on both sides of Eq. (11), we can get :

$$
\begin{aligned}
& \ln \left(G T F P_{i, t}\right)= \ln \xi \\
&+\gamma \sum_{j=1}^{n} \omega_{i, j} \ln \left(T_{i, t}\right)-\gamma \ln \left(G T F P_{i, t}\right) \sum_{j=1}^{n} \omega_{i, j}+\zeta \ln \left(A T_{i, t}\right) \\
&+\zeta \gamma \sum_{j=1}^{n} \omega_{i, j} \ln \left(A T_{j, t}\right)
\end{aligned}
$$

184

$$
\ln \left(G T F P_{i, t}\right)=\frac{\ln \xi}{1+\gamma}+\frac{\gamma}{1+\gamma} \sum_{j=1}^{n} \omega_{i, j} \ln \left(T_{i, t}\right)+\frac{\zeta}{1+\gamma} \ln \left(A T_{i, t}\right)+\frac{\zeta \gamma}{1+\gamma} \sum_{j=1}^{n} \omega_{i, j} \ln \left(A T_{j, t}\right)
$$

185

$$
\begin{gathered}
\ln \left(G T F P_{i, t}\right)=\frac{\ln \xi}{1+\gamma}+\frac{\gamma}{1+\gamma} \sum_{j=1}^{n} \omega_{i, j} \ln \left(T_{i, t}\right)+\frac{\zeta}{1+\gamma} \ln \rho_{i}+\frac{\zeta \gamma}{1+\gamma} \ln \left(C I_{i, t}\right)+\frac{\zeta \gamma}{1+\gamma} \ln \rho_{j} \\
\quad-\frac{\zeta \gamma^{2}}{1+\gamma} \sum_{j=1}^{n} \omega_{i, j} \ln \left(C I_{j, t}\right)
\end{gathered}
$$

The Eq. (14) shows that the average technical level of each region has a positive effect on green total factor productivity. The level of local collaborative innovation has a positive effect on the local green total factor productivity. While the level of collaborative innovation in surrounding regions has negative effect on the local green total factor productivity. When the technical level of the region is higher than that of the surrounding area, the level of local collaborative innovation has a greater positive effect on local green total factor productivity.

191 When the technical level of the region is lower than that of the surrounding area, the level of collaborative innovation in the surrounding area has a greater negative effect on local green total factor productivity. In 
comparison, when $0<\gamma<1$, the regional collaborative innovation has a positive effect on the regional green total

194 factor productivity and the effect is larger. When $\gamma>1$, due to spatial interaction, local collaborative innovation

195 has a negative effect on green total factor productivity in the surrounding areas and the effect is larger. Overall,

196 when the regional technology gap is small, collaborative innovation has a positive impact on local green total

197 factor productivity. When the regional technology gap is too large, collaborative innovation has a negative impact

198 on green total factor productivity in surrounding areas.

4 Calculation and analysis of collaborative innovation level in

202 Yangtze River Economic Belt

\subsection{Measurement index of collaborative innovation}

At present, collaborative innovation plays an increasingly important role in economic development and has become an important way and core driving force to realize the coordinated development of a country or region's economy ( $\mathrm{Li}$ and $\mathrm{Wu}$ 2019). Researchers have given different connotations of collaborative innovation and interpreted collaborative innovation from the perspectives of innovation subject collaboration, innovation factor flow, collaborative innovation organization model and collaborative innovation content. For example, Chen and Yang (2012) believed that collaborative innovation is a large-span integrated innovation organization model for enterprises, governments, knowledge production institutions ( universities, research institutions ), intermediaries and users to achieve major scientific and technological innovation. Bai and Jiang (2015) believed that

212 collaborative innovation includes not only the innovation achievements obtained by the integration of resources

213 through collaborative cooperation among innovation subjects but also the collaborative innovation effect formed

214 by the flow of regional innovation elements among regions. Wang and Wei (2016) think collaborative innovation includes knowledge innovation and technology innovation.

This paper believes that collaborative innovation is a technological innovation process based on the

217 collaborative integration of innovation resources among different innovation subjects under the support of 218 collaborative innovation environment. To a certain extent, the collaborative innovation process is the technological 219 innovation process (He and Qiao 2015). Therefore, the collaborative innovation process is composed of two 220 aspects of innovation factor collaboration and innovation environment collaboration. The synergy of innovation 
221 elements refers to the process that collaborative innovation subjects invest certain innovation resources to achieve

222 scientific and technological output and transform technological achievements to achieve economic benefits. It

223 reflects the research and development of innovation achievements and its application in the production stage,

224 mainly including the synergy of funds, personnel and knowledge. Innovation environment synergy refers to the

225 integration of external supporting environment for collaborative innovation, mainly including the synergy of

226 external environment such as government policies, finance and human resources. Research shows that

227 collaborative innovation is inseparable from the support of innovation environment, which provides survival

228 support for innovation subjects (Fei and Ling 2019). According to Albert's research (Albert et al. 2013), the

229 number and impact of collaborative innovation research results have been greatly improved with government

230 funding. According to King and Levine's (1993) research, financial institutions have a great probability to promote

231 the innovation process. Therefore, based on the collaborative innovation process, this paper constructs the

232 evaluation index system of collaborative innovation level from two aspects of innovation element synergy and

233 innovation environment synergy. The specific indicator system is shown in Table 1.

234

235

Table.1 Collaborative innovation evaluation index

\begin{tabular}{|c|c|c|c|}
\hline & Indictors & Specific indictors & Unit \\
\hline \multirow{9}{*}{$\begin{array}{l}\text { Synergy of innovation } \\
\text { elements }\end{array}$} & \multirow{4}{*}{ Fund synergy } & $\begin{array}{l}\text { External R\&D expenditure of industrial enterprises above } \\
\text { designated size }\end{array}$ & Million yuan \\
\hline & & $\begin{array}{l}\text { External expenditure on R\&D funds in institutions of higher } \\
\text { learning }\end{array}$ & Million yuan \\
\hline & & $\begin{array}{l}\text { R\&D external expenditure of research and development } \\
\text { institutions }\end{array}$ & Million yuan \\
\hline & & $\begin{array}{l}\text { Internal Expenditure of R\&D Funds for Universities and } \\
\text { Research Institutions from Enterprises }\end{array}$ & Million yuan \\
\hline & \multirow{3}{*}{$\begin{array}{l}\text { Staff } \\
\text { coordination }\end{array}$} & $\begin{array}{l}\text { Authors' scientific papers from the same province and } \\
\text { different units }\end{array}$ & $\%$ \\
\hline & & Author 's Sci - tech Papers & $\%$ \\
\hline & & Author of Foreign Scientific Papers & $\%$ \\
\hline & \multirow{2}{*}{$\begin{array}{l}\text { Knowledge } \\
\text { synergy }\end{array}$} & Technology market turnover & Million yuan \\
\hline & & $\begin{array}{l}\text { Ten thousand science and technology intermediary service } \\
\text { personnel }\end{array}$ & People \\
\hline \multirow{3}{*}{$\begin{array}{l}\text { Innovation } \\
\text { environment synergy }\end{array}$} & $\begin{array}{l}\text { Policy } \\
\text { coordination }\end{array}$ & Government funds in regional R\&D funds & Million yuan \\
\hline & $\begin{array}{l}\text { Financial } \\
\text { coordination }\end{array}$ & Financial Institution Funds in Regional R\&D Funds & Million yuan \\
\hline & Social & Ten thousand Internet users & People/Million \\
\hline
\end{tabular}




\subsection{Calculation method of collaborative innovation}

The measured methods of collaborative innovation include factor analysis, principal component analysis and evaluation index system. For example, Yang and $\mathrm{Li}$ (2019) use factor analysis to extract the common factors between innovation subjects as a measure of collaborative innovation and calculate the corresponding score to measure collaborative innovation. Wu et al. (2016). used principal component analysis to measure collaborative innovation capability. Huang and Xie (2016) used principal component-correlation coefficient method to construct collaborative innovation measurement method. In addition to the above methods, Li and Liu (2020) used the

244 extended DEA method to measure the level of collaborative innovation. Based on the above literature research, this paper selects entropy method to calculate collaborative innovation according to Zheng et al 's (2010) research. Entropy method is an effective method for multi-index comprehensive evaluation of regional development. In this paper, the weight of each index in each province of the Yangtze River Economic Belt is calculated and then the comprehensive index of collaborative innovation is obtained by multiplying each index and its weight. The process is as follows :

(1) Dimensionless treatment of indicators. The indicators selected in this paper are positive indicators, so dimensionless processing formula :

$$
X_{i j}=\frac{x_{i j}-\min \left(x_{j}\right)}{\max \left(x_{j}\right)-\min \left(x_{j}\right)}
$$

(2) Coordinate translation and normalization of dimensionless data. Where A is the translation distance, the value is selected as 1 .

$$
Y_{i j}=X_{i j}+A ; \quad P_{i j}=\frac{Y_{i j}}{\sum_{i=1}^{m} Y_{i j}}
$$

(3) Calculation of index information entropy and difference coefficient. $K=1 / 1 \mathrm{nn}, \mathrm{n}$ is the number of samples.

$$
e_{j}=-K \sum_{i=1}^{m} P_{i j} \ln P_{i j} ; d_{j}=1-e_{j}
$$

(4) Calculation of index weight. 


$$
\omega_{j}=\frac{d_{j}}{\sum_{i=1}^{n} d_{j}}
$$

\subsection{Analysis of collaborative innovation calculation results of Yangtze River}

\section{Economic Belt}

This paper calculates the overall level of collaborative innovation in the Yangtze River Economic Belt from 2009 to 2017, as well as the sub-data of financial synergy, personnel synergy, knowledge synergy and environmental synergy, and converts the level of collaborative innovation into graphic representation ( limited to length, this paper does not list the results of relevant calculations, which can be obtained from the author if necessary ).

From A and B in Figure 2, it can be seen that since 2009, the level of collaborative innovation in each province of the Yangtze River Economic Belt has been increasing year by year. Further subregionally, the collaborative innovation level of the Yangtze River Economic Belt shows the characteristics of 'high in the middle reaches, middle in the downstream and low in the upstream'. However, the level of downstream collaborative innovation grew rapidly, from near upstream provinces in 2009 to near midstream provinces. From the perspective of a single province, there are Shanghai, Yunnan, Anhui and Hubei provinces above the average level of overall collaborative innovation. However, there are Zhejiang, Jiangxi, Hunan, Sichuan, Jiangsu, Chongqing and Guizhou provinces below the average level of overall collaborative innovation. It not only further explains the regional differences in the level of collaborative innovation in the Yangtze River Economic Belt but also shows that there is a significant deviation between the level of regional collaborative innovation and the level of economic development, which is consistent with Zhao Zhe 's conclusion that the performance of collaborative innovation and its contribution to economic growth are not significant (Zhao 2020).

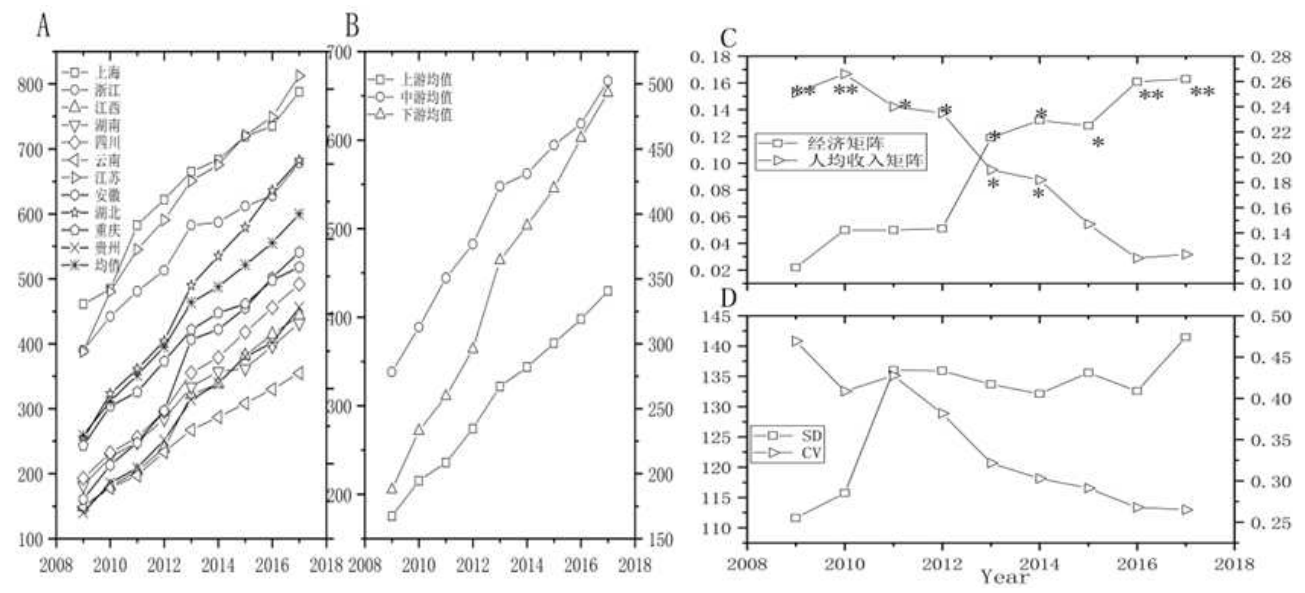


278 Note: A. The level and mean change of collaborative innovation in the provinces of the Yangtze River 279 Economic Belt B. The mean change of regional collaborative innovation C. Moran 's I value of collaborative 280 innovation corresponding to different matrices D. Standard deviation and coefficient of variation of collaborative innovation

Figure $\mathrm{C}$ in Figure 2 shows the self-correlation coefficient of collaborative innovation space under different spatial weight matrices. The economic matrix uses the reciprocal of GDP gap as the weight to measure the 'adjacent' degree between provinces and the per capita income matrix uses the reciprocal of per capita income gap as the weight to measure the 'adjacent' degree between provinces. The map shows that the Moran's I value of the spatial autocorrelation coefficient of collaborative innovation calculated under the economic matrix is positive and passed the test from 2013 to 2019 at different significant levels. The Moran's I value of the spatial autocorrelation coefficient of collaborative innovation calculated under the per capita income matrix is positive and passed the test from 2009 to 2013 at different significant levels. The corresponding Moran's I values under different matrices show that collaborative innovation is positively correlated in space and the global Moran's I value changes little, indicating that the spatial distribution pattern of collaborative innovation is relatively stable and there is no large change. It can be seen from Figure D in Figure 2 that the standard difference corresponding to collaborative innovation changes greatly before 2011, tending to be stable from 2011 to 2017 . The corresponding coefficient of variation tends to increase between 2010 and 2011 and the coefficient of variation at other time stages decreases year by year. It is believed that there is $\sigma$ convergence in collaborative innovation, which is mainly due to the agglomeration of high-tech innovation bases. Under the effect of agglomeration-diffusion effect, regions with high

297 level of scientific and technological innovation can promote the development of regions with low level of scientific and technological innovation.

\section{Empirical design}

\subsection{Indicator selection}

(1) Explained variable: green total factor productivity. Green total factor productivity is an input-output

303 efficiency that considers energy and resource consumption. It is an important guarantee for transforming mode of economic development and achieving sustainable economic growth. 
by Chsrnes, Cooper and Rhodes (Charnes et al. 1979). Since it is unnecessary to determine the specific form and estimated parameters of the model, it has been widely used. However, because it is a radial and angle measurement method, it will lead to overestimation of efficiency value and inaccurate results. Therefore, this paper selects Tone's SSBM model(Tone 2001;2002) based on the undesirable output SBM model and the idea of superefficiency model :

$$
\min \rho=\frac{1}{m} \sum_{i=1}^{m} \frac{\overline{\mathrm{x}}}{x_{i k}} \frac{1}{s_{1}+s_{2}}\left(\sum_{r=1}^{s_{1}} \frac{\bar{y}^{g}}{y_{s k}^{g}}+\sum_{q=1}^{s_{2}} \frac{\bar{y}^{b}}{y_{q k}^{b}}\right)
$$

$$
\left\{\begin{array}{c}
\overline{\mathrm{x}} \geq \sum_{j=1, \neq k}^{n} x_{i j} \lambda_{j} ; \bar{y}^{g} \leq \sum_{j=1, \neq k}^{n} y_{s j}^{g} \lambda_{j} ; \bar{y}^{g} \geq \sum_{j=1, \neq k}^{n} y_{q j}^{g} \lambda_{j} \\
\overline{\mathrm{x}} \geq x_{k} ; \bar{y}^{g} \leq y_{k}^{g} ; ; \bar{y}^{b} \geq y_{k}^{b} \\
\lambda_{j} \geq 0, i=1,2, \cdots, m ; j=1,2, \cdots, n ; \\
\mathrm{j} \neq 0 ; \mathrm{s}=1,2, \cdots, \mathrm{s}_{1} ; \mathrm{q}=1,2, \cdots, \mathrm{s}_{2}
\end{array}\right.
$$

$\rho$ is the efficiency evaluation value; $x, y^{g} y^{b}$ respectively represent input indicators, expected output

314 indicators, unexpected output indicators; $n$ is the number of DMUs; $m$ is the number of input indicators; $s_{1}$ is the number of expected output indicators; $s_{2}$ is the number of unexpected output indicators.

In this paper, the input indicators used to calculate green total factor productivity are labor, energy and capital. On labor input, referring to the study of most scholars in total factor productivity research, this paper select the provinces over the years of employment as a substitute indicator. With regard to energy input, taking into account the regional differences in energy consumption types, the total regional energy consumption equivalent to standard coal is selected as a substitute indicator. Regarding the capital stock index, we choose the total amount of fixed capital formation to measure and use the perpetual inventory method for conversion. The investment price index is replaced by the fixed asset investment price index of each province. And the depreciation rate is determined to be $10.96 \%$ based on the existing research (Zhang et al. 2004).

The expected output indicators in output are replaced by regional GDP and are reduced to constant price levels based on 2000. In terms of undesirable output, using Chen Shiyi's (Chen 2009) method to calculate the total $\mathrm{CO}_{2}$ emissions of each province or city as the undesirable output index of the region. The specific indicators are shown in Table 2. 
Table 2 Green Total Factor Productivity Indicators

\begin{tabular}{llc}
\hline Indictors & Specific indictors & Unit \\
\hline Labour & Employees at the end of the year & Million people \\
Energy source & Total energy consumption & Ten thousand tons of standard coal \\
Capital & Stock of capital & Billion yuan \\
Expected output & Gross domestic product & Ton
\end{tabular}

(2) Explanatory variables: collaborative innovation level. This paper uses the measurement data of the overall

331 level of collaborative innovation of provinces and cities in the Yangtze River Economic Belt calculated above.

332 (3) Other control variables. Based on the research of other scholars, this paper selects five types of control 333 indicators, including environmental protection $(E P)$, human capital $(H C)$, industrial structure (IS), fiscal 334 expenditure $(M F)$ and openness $(O P)$. Considering the attributes of public goods and positive externalities of 335 environmental resources, this paper uses environmental protection expenditure to measure government investment 336 in environmental protection and then measures the specific relationship between environmental protection and economic development. Human capital is calculated and characterized by the formula of the proportion of primary 338 school students $* 6+$ the proportion of junior high school students $* 9+$ the proportion of high school students * $33912+$ the proportion of college students and above $* 16$. The industrial structure of this paper selects the tertiary 340 industry output value and GDP ratio to measure. Fiscal expenditure is characterized by the ratio of regional fiscal expenditure to regional GDP. The degree of opening to the outside world is measured by the ratio of regional

342 import and export volume to regional GDP; meanwhile, the RMB is converted according to the exchange rate of 343 the year. Before the model regression, the data are dimensionless to eliminate the impact of dimension.

\subsection{Model construction}

In order to reveal the influence mechanism of spatial factors on green total factor productivity, this paper uses

347 spatial econometric model analysis. This model is mainly divided into spatial lag model and spatial error model.

348 Because different regional subjects in the innovation network can share the knowledge spillover effect of the 349 network (Gao and Zhang 2019), the spatial correlation between regions is considered in the classical regression model, namely the SDM model : 


$$
G T F P=\beta_{0} t_{0}+\rho T W G T F P+X B_{1}+T W X B_{2}+U_{1}
$$

GTFP is the explained variable matrix of $N T \times 1$ order, which represents the pool accumulation sequence of green total factor productivity in the Yangtze River Economic Belt. $N$ is the number of provinces in the Yangtze River Economic Belt, $\mathrm{T}$ is the time span.and $t_{0}$ is a matrix with $N T \times 1$ elements and its value is $1 . \beta_{0}$ is an empirical constant and $\rho$ is the spatial correlation coefficient, which is between -1 and $1 . X$ is the explanatory variable matrix of $N T \times K_{1}$, which represents the pool accumulation sequence of possible influencing factors affecting the green total factor productivity of the Yangtze River Economic Belt, where $K_{1}$ is the number of explanatory variables. $T W$ is a space-time weight matrix of $N T \times N T$ order and its construction method is based on the research of Fan Qiao (Fan and Hudson 2018). The spatial weight matrix uses the economic matrix to represent the spatial spillover effect between different regions. The time weight matrix is based on the ratio of global Moran index in different years to reflect the transfer and conduction effects of spatial spillover effects with time. $B_{1}$ and $B_{2}$ are the parameter matrices of order $K_{1} \times 1$ respectively, representing the parameters of explanatory variables. $U_{1}$ is a random perturbation matrix of order $N T \times 1$, obeying the multidimensional normal distribution of mean 0 and variance $\sigma^{2} I_{N T}$, where $\sigma^{2}$ is a constant and $I_{N T}$ is a unit matrix of order $N T$.

\subsection{Data sources and descriptive statistics}

The specific indicators involved in this paper come from 《China Statistical Yearbook》, 《China Energy Statistics Yearbook》, 《China Statistical Yearbook of Science and Technology》, 《China Torch Statistical Yearbook》, 《China Urban Statistical Yearbook》, 《China Regional Innovation Capacity Report》, National Bureau of Statistics and 《China Environmental Yearbook》. The data in this paper is provincial panel data and the time span is 2009-2017. The missing values are added by interpolation method. Data units and descriptive statistical results are shown in Table 3 . 
Table 3 Definitions of indicators and descriptive statistics

\begin{tabular}{|c|c|c|c|c|c|}
\hline Variable & Abbreviation & Min & Max & Mean & Std.Dev \\
\hline $\begin{array}{l}\text { Green total } \\
\text { factor productivity }\end{array}$ & GTFP & 0.5589 & 1.0797 & 0.8772 & 0.1270 \\
\hline $\begin{array}{l}\text { Collaborative } \\
\text { innovation }\end{array}$ & $C I$ & 134.7156 & 787.8208 & 393.3115 & 157.4185 \\
\hline $\begin{array}{l}\text { Environmental } \\
\text { protection }\end{array}$ & $E P$ & 33.8565 & 370.5800 & 114.0964 & 63.2179 \\
\hline Human capital & $H C$ & 707.6400 & 1258 & 926.3138 & 109.1207 \\
\hline $\begin{array}{l}\text { Industrial } \\
\text { structure }\end{array}$ & $I S$ & 32.5000 & 69.7800 & 43.9085 & 7.9991 \\
\hline $\begin{array}{l}\text { Financial } \\
\text { expenditure }\end{array}$ & $M F$ & 15.2106 & 77.0465 & 34.4159 & 14.8395 \\
\hline $\begin{array}{l}\text { Opening to the } \\
\text { outside world }\end{array}$ & $O P$ & 6.1161 & 198.3146 & 43.0680 & 48.3082 \\
\hline
\end{tabular}

378

3795.4 Impact of collaborative innovation on green total factor 380 productivity

\subsubsection{Regression results and analysis}

382 This paper first tests the panel data. ADF method is used to test the panel data stability and the conclusion is

383 that the data is stable. Through Kao, Pedroni, Westerlund and other test variables cointegration relationship, this

384 paper found that there is a cointegration relationship between the variables, the results show that it can carry out

385 the next measurement operation. The specific test results are shown in Tables 4 and Table 5.

386

387

Table 4 Stability Test of Panel Data

\begin{tabular}{ll}
\hline Variable & ADF \\
\hline$G T F P$ & $247.0981^{* * *}$ \\
$C I$ & $57.3512^{* * *}$ \\
$E P$ & $393.3000^{* * *}$
\end{tabular}




\begin{tabular}{ll}
\hline Variable & ADF \\
\hline$H C$ & $42.1305^{* * *}$ \\
$I S$ & $63.6096^{* * *}$ \\
$M F$ & $160.0482^{* * *}$ \\
$O P$ & $66.0959^{* * *}$
\end{tabular}

Note $: *, * *, * * *$ are significant at the level of $10 \% 、 5 \% 、 1 \%$ respectively.

\begin{tabular}{ll}
\hline Cointegration test & Results of inspection \\
\hline Kao & $-1.5219^{*}$ \\
Pedroni & $5.8223^{* * *}$ \\
Westerlund & $1.5993^{*}$ \\
\end{tabular}

Note $: * * *, * * *$ are significant at the level of $10 \%, 5 \%, 1 \%$ respectively. matrix is calculated, which is transformed into a visual graph, as shown in Figure 3 below.

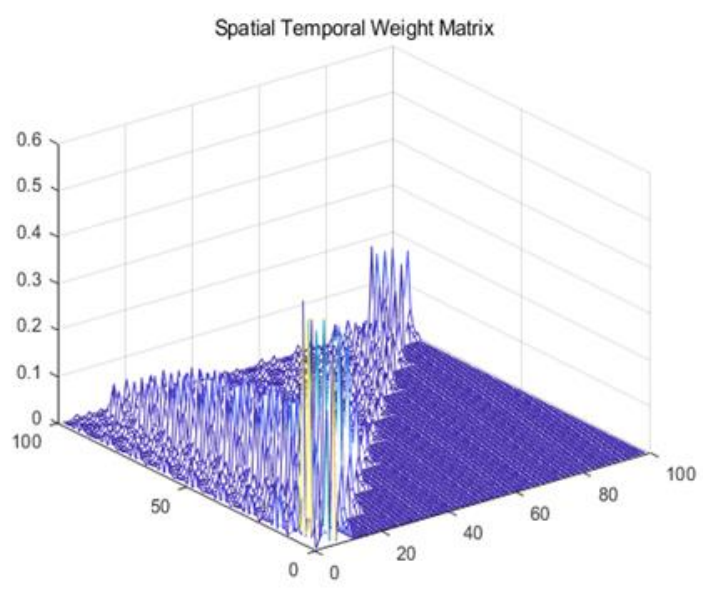

Fig 3. Endogenous space-time weight matrix based on economic matrix 
results are shown in Table 6. From the regression results, without considering the spatial interaction effect, it is

401 found that the regression coefficients of environmental protection, human capital and industrial structure are all

402 positive and pass the test at the significance level of $1 \%$, indicating that the three have a positive role in promoting

403 the green total factor productivity of the Yangtze River Economic Belt. However, collaborative innovation, fiscal

404 expenditure and opening up did not pass the significant test, indicating that the impact of the three on green total

405 factor productivity is uncertain.

In the case of introducing space-time interaction effect, the regression coefficient of collaborative innovation

407 is negative and the test is passed at $1 \%$ significance level, indicating that the level of collaborative innovation in

408 the surrounding areas has a significant negative effect on the green total factor productivity of the region.

409 Collaborative innovation is based on the flow of knowledge and technology. The improvement of collaborative innovation level in surrounding areas means that innovative resources and achievements will flow out, which has a

411 negative impact on technological innovation and green economic development. The regression coefficient of

412 environmental protection and opening up is significantly positive, indicating that the improvement of the two in

413 the surrounding areas has obvious spatial interaction effect on the improvement of local green total factor

414 productivity. As public goods, when the environmental protection level in the surrounding areas is high, the

415 environmental protection in the region also has a promoting effect, which will further improve the development of

416 green economy. The opening up can promote the economic growth and technological progress of the region and

417 the spillover effect affects the surrounding areas. The regression coefficient of fiscal expenditure is significantly

418 negative, indicating that fiscal expenditure in surrounding areas inhibits the improvement of local green total

419 factor productivity. The reason is that fiscal expenditure in each region is mostly used around the region and aims

420 at economic growth. Economic growth in surrounding areas will form a siphon effect on local resources and

421 inhibit the development of local green economy. The human capital and industrial structure did not pass the

422 significant test, indicating that the spatial spillover effect of human capital and industrial structure changes in

423 surrounding areas on local green total factor productivity is uncertain.

Table 6 SDM regression estimation results of endogenous spatio-temporal weight matrix based on economic matrix

\begin{tabular}{lccc}
\hline Variable & SDM & t-value & p-value \\
\hline$C I$ & 0.0175 & 0.0800 & 0.9362 \\
\hline
\end{tabular}




\begin{tabular}{|c|c|c|c|}
\hline Variable & SDM & t-value & p-value \\
\hline$E P$ & $0.7475^{* * *}$ & 5.93 & 0.0000 \\
\hline$H C$ & $0.3832^{* * *}$ & 2.69 & 0.0071 \\
\hline$I S$ & $0.6611^{* * *}$ & 4.61 & 0.0000 \\
\hline$M F$ & 0.0331 & 0.31 & 0.7549 \\
\hline$O P$ & -0.1106 & -0.65 & 0.5147 \\
\hline$T W \times C I$ & $-2.5585^{* * *}$ & -6.21 & 0.0000 \\
\hline$T W \times E P$ & $1.3903^{*}$ & 1.87 & 0.0612 \\
\hline$T W \times H C$ & -0.3039 & -0.96 & 0.3369 \\
\hline$T W \times I S$ & -0.6502 & -1.57 & 0.1164 \\
\hline$T W \times M F$ & $-1.6430^{* * *}$ & -6.29 & 0.0000 \\
\hline$T W \times O P$ & $0.9955^{* *}$ & 2.30 & 0.0217 \\
\hline rho & -0.1830 & -0.98 & 0.3276 \\
\hline Sigma2_e & 0.0126 & & \\
\hline Log-likelihood & 110.0900 & & \\
\hline$R^{2}$ & 0.7881 & & \\
\hline
\end{tabular}

Note $: * * *, * * *$ are significant at the level of $10 \%, 5 \%, 1 \%$ respectively.

\subsubsection{Effect decomposition}

430 Since regions are interrelated, the spatial interaction of some economic variables does not affect the local

431 economy but affect the economy of neighboring regions. That is to say, there is an external effect. Therefore, this

432 paper decomposes the effect of mixed effect SDM model based on endogenous space-time weight matrix to obtain

433 direct effect and indirect effect. Generally speaking, direct effects represent the impact of explanatory variables on

434 the region and indirect effects represent the impact of explanatory variables on other regions. The decomposition results are shown in Table 7.

Table 7 Direct effect, indirect effect and total effect decomposition of mixed effect SDM model based on endogenous time-space weight matrix of economic matrix

\begin{tabular}{cccc}
\hline Variable & Direct effect & Indirect effect & Total effect \\
\hline$C I$ & 0.0577 & $-2.2187^{* * *}$ & $-2.1610^{* * *}$
\end{tabular}




\begin{tabular}{cccc}
\hline Variable & Direct effect & Indirect effect & Total effect \\
\hline \multirow{2}{*}{$E P$} & $(0.27)$ & $(-5.44)$ & $(-4.42)$ \\
& $0.7302^{* * *}$ & 1.1312 & $1.8614^{* *}$ \\
\multirow{H}{*}{$H C$} & $(5.84)$ & $(1.46)$ & $(2.18)$ \\
& $0.3848^{* *}$ & -0.3479 & 0.0369 \\
\multirow{2}{*}{ IS } & $(2.62)$ & $(-1.25)$ & $(0.13)$ \\
& $0.6671^{* * *}$ & $-0.6770^{*}$ & -0.0099 \\
MF & $(4.45)$ & $(-1.78)$ & $(-0.03)$ \\
& 0.0533 & $-1.4356^{* * *}$ & $-1.3823^{* *}$ \\
& $(0.50)$ & $(-5.41)$ & $(-5.92)$ \\
$O P$ & -0.1257 & $0.8694^{* *}$ & $0.7438^{* *}$ \\
& $(-0.73)$ & $(2.23)$ & $(2.21)$ \\
\hline
\end{tabular}

438 Note: The number in brackets is the t-statistics of the coefficient, and $* * *, * * *$ represent the significance 439 at the levels of $10 \%, 5 \%$ and $1 \%$, respectively.

440 The results of Table 7 show that the direct effect of collaborative innovation is not significant but the indirect

441 effect is very significant and the coefficient is large, which has a significant inhibitory effect on the green total

442 factor productivity in the surrounding areas. The results are consistent with the regression results of spatial effect

443 in SDM model. Overall, the total effect reflects that the level of collaborative innovation in various regions has a

444 significant impact on the growth of green total factor productivity in terms of spatial interaction. Since the 445 inhibitory effect of collaborative innovation in the region on green total factor productivity in surrounding areas is

446 too strong, it is not conducive to improving the green total factor productivity level in the Yangtze River Economic

447 Belt. On the one hand, it shows that collaborative innovation does not necessarily aim at green efficiency but may

448 be at the cost of high consumption and high output, thereby inhibiting the growth of green total factor productivity

449 (Zhao and Chen 2020). On the other hand, it shows that the effect of collaborative innovation in backward areas

450 may not be obvious when the technical level gap is too large.

451 The direct effect of environmental protection and human capital is very significant, which can greatly 452 promote the growth of local green total factor productivity. However, its indirect effect is not significant, 453 indicating that its spatial spillover effect is insufficient. Under the impact of this indirect effect, the total effect is 454 differentiated. That is to say, environmental protection has significantly promoted the growth of regional green 455 total factor productivity, while human capital has little effect on the growth of regional green total factor 456 productivity. In general, the growth of human capital will promote the growth of total factor productivity 
457 (Benhabib and Spiegel 1994). And if human capital is mismatched or under-matched, it will also lead to the 458 reduction of green total factor productivity (Lai and Ji 2015).

The direct effect of industrial structure upgrading is very significant, which greatly promotes the growth of green total factor productivity in the region. However, its indirect effect shows that it has a significant inhibitory effect on the green total factor productivity in the surrounding areas. The reason is that the rational allocation of factors and dynamic equilibrium effect caused by industrial structure optimization can promote the growth of green total factor productivity in the region and inhibit the growth of green total factor productivity in the surrounding areas through the radiation effect caused by the correlation between industrial chains and industrial agglomeration.

The direct effect of fiscal expenditure index is not significant, while its indirect effect is very significant. The results show that the growth of green total factor productivity in the surrounding areas is greatly inhibited and its total effect also reflects a significant inhibitory effect, which is consistent with the regression results in the SDM model. This may be due to the negative impact of fiscal policies aimed at promoting economic growth on the environment, resulting in no significant contribution to productivity growth (Zhu and Li 2019). This shows that the implementation of the current 'green finance' strategy needs to adopt diversified means other than green special funds and green government procurement to promote the sustainable growth of green economy.

The direct effect of openness index is not significant, while its indirect effect is very significant. The results show that it greatly promotes the growth of green total factor productivity in surrounding areas and its total effect also reflects a significant promotion effect, which is consistent with the regression results of spatial effect in the SDM model. The reason is that, as mentioned above, it is caused by the spatial spillover effect of economy and technology.

\subsubsection{Robustness test}

Considering the need for robustness test of spatial measurement, this paper selects alternative indicators to recalculate the endogenous spatio-temporal weight matrix. Because there are many alternative indicators that can be used to calculate the economic matrix, this paper selects per capita income as an alternative indicator to calculate the economic matrix to recalculate the endogenous space-time weight matrix. Figure 4 below shows. 


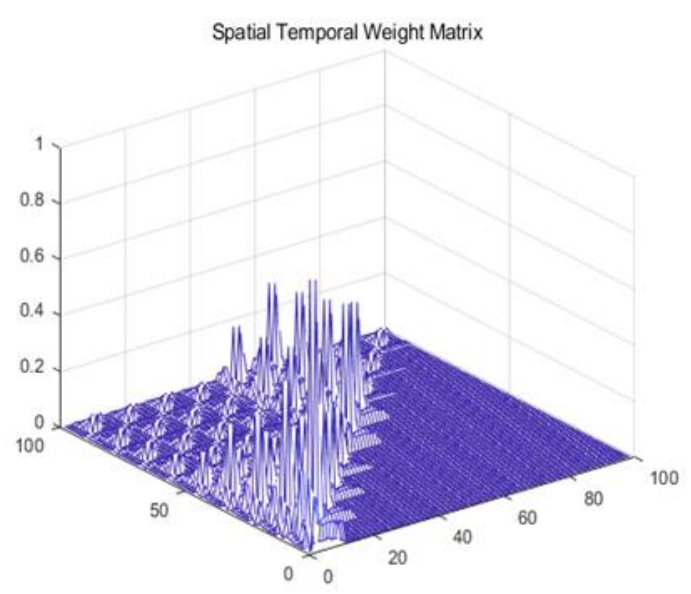

484

Fig 4. Endogenous time-space weight matrix based on per capita income matrix

Then, the effect of SDM model based on the mixed effect of endogenous time-space weight matrix based on per capita income matrix is decomposed. And the direct effect and indirect effect are obtained to do stability test, comparing with the previous calculation results. The specific results are shown in Table 8 .

489

Table 8 Direct effect, indirect effect and total effect decomposition of mixed effect SDM model based on endogenous time-space weight matrix of per capita income matrix

\begin{tabular}{llll}
\hline Variable & Direct effect & Indirect effect & Total effect \\
\hline CI & 0.0588 & $-2.2086^{* * *}$ & $-2.1499^{* * *}$ \\
& $(0.28)$ & $(-5.63)$ & $(-4.47)$ \\
$E P$ & $0.7282^{* * *}$ & 1.0824 & $1.8106^{* *}$ \\
& $(6.07)$ & $(1.47)$ & $(2.24)$ \\
$H C$ & $0.3836^{* * *}$ & -0.3256 & 0.0580 \\
& $(2.78)$ & $(-1.15)$ & $(0.20)$ \\
$I S$ & $0.6715^{* * *}$ & $-0.6727^{*}$ & -0.0013 \\
& $(4.44)$ & $(-1.85)$ & $(-0.004)$ \\
$M F$ & 0.0588 & $-1.4400^{* * *}$ & $-1.3813^{* *}$ \\
& $(0.54)$ & $(-5.74)$ & $(-6.39)$ \\
$O P$ & -0.1314 & $0.8960^{* *}$ & $0.7646^{* *}$ \\
& $(-0.77)$ & $(2.35)$ & $(2.32)$
\end{tabular}


at the levels of $10 \%, 5 \%$ and $1 \%$, respectively.

494 It can be seen from Table 8 that no matter the total effect of the SDM model and the direct and indirect effects

495 obtained by decomposition, the sign and significance of the collaborative innovation variable are completely

496 consistent with the empirical results above, indicating that the transformation of the endogenous spatio-temporal

497 weight matrix does not change the previous conclusion. Furthermore, the symbols and significance of the other

498 five control variables are consistent with the previous empirical calculation results. All these conclusions prove 499 that the empirical results are still robust and the conclusions are also convincing even considering the differences 500 in the endogenous spatio-temporal weight matrix.

5026 Conclusion, discussion and policy implications

\subsection{Conclusion and discussion}

In this paper, the mathematical model is used to analyze the way that collaborative innovation affects regional green total factor productivity. Meanwhile, the evaluation index system of regional collaborative innovation level is constructed. The entropy method is used to calculate the collaborative innovation level of the Yangtze River Economic Belt and its evolution is analyzed. On this basis, the spatial Durbin model based on endogenous spatialtemporal weight matrix of economic matrix is used to explore the specific relationship between collaborative innovation and green total factor productivity in the Yangtze River Economic Belt.

And then the following conclusions are obtained: firstly, the level of collaborative innovation in each province of the Yangtze River Economic Belt shows an upward trend year by year, which is characterized by 'high in the middle reaches, middle in the downstream and low in the upstream'. The level of collaborative innovation in

513 the Yangtze River Economic Belt has a positive spatial correlation and $\sigma$ convergence. Secondly, collaborative 514 innovation in the Yangtze River Economic Belt has a significant negative impact on green total factor productivity 515 in terms of spatial interaction. And its impact on local green total factor productivity is not significant. Oppositely, the inhibitory effect on green total factor productivity in surrounding areas is very strong. Thirdly, environmental

517 protection and opening up in the Yangtze River Economic Belt have significant positive impact on green total 518 factor productivity in terms of spatial interaction. However, the former mainly affects local green total factor 519 productivity, while the latter mainly affects green total factor productivity in surrounding areas. Fiscal expenditure has significant negative spatial effect on green total factor productivity, mainly inhibiting the growth of green total 
factor productivity in surrounding areas. The spatial interaction between industrial structure and human capital on green total factor productivity is not obvious.

\subsection{Policy implications}

According to above conclusions, following suggestions are proposed to improve green total factor productivity and collaborative innovation:

Firstly, it is necessary to further strengthen regional collaborative innovation. Through the coordination of science and technology innovation policy, it provides a good policy environment for collaborative innovation, gives full play to the role of intermediary service institutions, improves the supporting environment of collaborative innovation, promotes the flow and sharing of innovation personnel, funds and knowledge resources and maximizes the enthusiasm of innovation subjects. It is also indispensable to strengthen the transformation of collaborative innovation results in order to accelerate the reduction of regional technical level differences and promote the transformation, promotion and application of collaborative innovation achievements. Speed up the improvement of technology market and relevant laws and regulations, establish incentive and supervision mechanism for the transformation of innovation achievements and improve the positive feedback level of collaborative innovation.

Secondly, it is necessary to further strengthen environmental protection. Give full play to the spatial spillover

538 effect of environmental protection, strengthen the coordination of regional environmental policies and accelerate the rational use of ecological environmental protection big data in environmental quality improvement and regional cooperation will improve the efficiency of green economy. By optimizing the industrial structure and layout, improve the energy consumption structure and actively develop energy saving and environmental

542 protection technology will contribute to promoting the development of green economy. Through diversified 543 industrial development, expanding the industrial chain and increasing the radiation effect of environmental 544 protection industry for economic development will contribute to promoting the development of green economy. local governments, increase the 'green expenditure' in fiscal expenditure and guide the flow of funds to green industries will promote the transformation of economy to green. Continue to adhere to opening up. Pay special attention to the development of foreign trade green industry and increase the export of green goods. Pay attention 


\section{Declarations}

\section{Ethics approval and consent to participate}

554

Not applicable

\section{Consent for publication}

Not applicable

\section{Competing interests}

The authors declare that they have no known competing financial interests or personal relationships that could have appeared to influence the work reported in this paper.

\section{Funding}

This research was jointly supported by the Open Funds of Regional Innovation Capabilities Monitoring and Analysis Soft Science Research Base of Hubei Province (Grant No. HBQY2021z05) and the Soft Science Research Projects of Hubei Science and Technology Support Plan (Grant No. 2017ADC138).

\section{Authors' contributions}

Lei Wu: Conceptualization, Formal analysis, Writing - review \& editing. Xiaoyan Jia: Conceptualization,

\section{References}


Bai, J. h, Jiang, F.X., 2015. Collaborative innovation, spatial correlation and regional innovation performance. J. Econ. Res. 50, 174-187. https://doi.org/CNKI:SUN:JJYJ.0.2015-07-014

Belderbos, R., Carree, M., Diederen, B., Lokshin, B., Veugelers, R., 2004. Heterogeneity in R\&amp;D cooperation strategies. Int. J. Ind. Organ. 22, 1237-1263. https://doi.org/10.1016/j.ijindorg.2004.08.001

Benhabib, J., Spiegel, M.M., 1994. The role of human capital in economic development evidence from aggregate cross-country data. J. Monet. Econ. 34, 143-173. https://doi.org/10.1016/0304-3932(94)90047-7

Broda, C., Greenfield, J., Weinstein, D., 2006. From Groundnuts to Globalization: A Structural Estimate of Trade and Growth. NBER Work. Pap. https://doi.org/10.1016/j.rie.2017.10.001

Charnes, A., Cooper, W.W., Rhodes, E., 1979. Measuring the efficiency of decision making units. Eur. J. Oper. Res. 2, 429-444. https://doi.org/10.1016/0377-2217(78)90138-8

Chen, J., Yang, Y.J., 2012. The theoretical basis and connotation of collaborative innovation. J. Stud. Sci. Sci. 30, 161-164. https://doi.org/10.16192/j.cnki.1003-2053.2012.02.001

Chen, S.Y., 2009. Energy consumption, carbon dioxide emissions and the sustainable development of China's industry. J. Econ. Res. 44, 41-55. https://doi.org/CNKI:SUN:JJYJ.0.2009-04-006

Chen, X., Wang, X., Zhou, M., 2019. Firms' green R\&amp;D cooperation behaviour in a supply chain: Technological spillover, power and coordination. Int. J. Prod. Econ. 218, 118-134. https://doi.org/10.1016/j.ijpe.2019.04.033

Dai, W.L., Li, D.Q., Li, Q.M., 2019. Analysis on the Contribution of Liaoning Coastal Economic Belt to the Collaborative Innovation of Industry, University and Research in Liaoning Province. J. Econ. Res. Guid. :47-50+97. https://doi.org/CNKI:SUN:JJYD.0.2019-07-021

Deng, Y., You, D., Wang, J., 2019. Optimal strategy for enterprises' green technology innovation from the perspective of political competition. J. Clean. Prod. 235, 930-942. https://doi.org/10.1016/j.jclepro.2019.06.248

Ertur, C., Koch, W., 2011. A contribution to the theory and empirics of Schumpeterian growth with worldwide interactions, Journal of Economic Growth. https://doi.org/10.1007/s10887-011-9067-0

Fan, D., Sun, X.T., 2020. Environmental regulation, green technology innovation and green economic growth. J. China Popul. Environ. 30, 105-115. https://doi.org/10.12062/cpre.20200123

Fan, Q., Hudson, D., 2018. A new endogenous space-time weight matrix construction method including variable time effects. J. Quant. Tech. Econ. 35, 131-149. https://doi.org/10.13653/j.cnki.jqte.20171228.007

Fei, Y.Y., Ling, L., 2019. Build an efficient national innovation ecosystem. J. People’s Forum 000, 62-63. https://doi.org/CNKI:SUN:RMLT.0.2019-18-025

Ganda, F., 2019. The impact of innovation and technology investments on carbon emissions in selected organisation for economic Co-operation and development countries. J. Clean. Prod. 217, 469-483. https://doi.org/10.1016/j.jclepro.2019.01.235

Gao, A.G., Zhang, L., 2019. The theoretical framework of inter-industry collaborative innovation across spaces from the perspective of knowledge heterogeneity: conditions, motivations and paths. J. Sci. Technol. Manag. Res. 39, 168-175. https://doi.org/10.3969/j.issn.1000-7695.2019.11.023

Gloor, P., 2006. Swarm Creativity: Competative Advantage Through Collaborative. Jounarl Innov. Manag. Policy Prat. 8, 413-414. https://doi.org/10.5172/impp.2006.8.4.413

Hao, J.L., Yin, M., 2019. Collaborative innovation of science and technology and economic growth in my country from the perspective of time and space differences. J. Econ. Manag. Rev. 35, 146-158. https://doi.org/10.13962/j.cnki.37-1486/f.2019.06.014 
He, X.G., 2015. Energy constraints, green technological innovation and sustainable growth - Theoretical models and empirical evidence. J. Zhongnan Univ. Econ. Law 30-38. https://doi.org/CNKI:SUN:ZLCJ.0.2015-04$\underline{004}$

He, Y.Q., Qiao, X.N., 2015. Collaborative innovation, collaborative innovation network and technological innovation. J. Beifang Univ. Natl. 133-136. https://doi.org/CNKI:SUN:XBDR.0.2015-02-027

Hu, Y., Pan, T., Zhang, W., 2019. Research on the Economic Growth Effect of Collaborative Innovation in the Yangtze River Delta City Group under the Integrated National Strategy. J. East China Norm. Univ. (Philosophy Soc. Sci. Ed. 51, 99-106+239. https://doi.org/10.16382/j.cnki.1000-5579.2019.05.011

Huang, X.R., Xie, R.H., 2016. Research on the Agglomeration of Scientific and Technological Resources and Regional Collaborative Innovation in the Yangtze River Economic Zone. J. Sci. Manag. Res. 53-56. https://doi.org/10.19445/j.cnki.15-1103/g3.2016.04.014

Jin, W., Zhang, Heng quan, Liu, S. shuang, Zhang, Hong bo, 2019. Technological innovation, environmental regulation, and green total factor efficiency of industrial water resources. J. Clean. Prod. 211, 61-69. https://doi.org/10.1016/j.jclepro.2018.11.172

Lai, D.S., Ji, W.W., 2015. Human capital allocation and innovation. J. Econ. Perspect. 22-30. https://doi.org/CNKI:SUN:JJXD.0.2015-03-004

Lee, J., Park, C., 2006. Research and development linkages in a national innovation system: Factors affecting success and failure in Korea. Technovation 26, 1045-1054. https://doi.org/10.1016/j.technovation.2005.09.004

Leydesdorff, L., Fritsch, M., 2006. Measuring the knowledge base of regional innovation systems in Germany in

Li, L., Liu, R., 2020. The impact of the flow of innovative elements on the collaborative innovation of urban agglomerations_-Based on the empirical study of the Yangtze River Delta urban agglomeration and the Yangtze River midstream. J. Sci. Technol. Manag. Res. 37, 56-63. https://doi.org/10.6049/kiibydc.2019090842

Li, Y.H., Wu, J.M., 2019. Collaborative innovation literature review. J. Xidian Univ. (Social Sci. Ed. 29, 1-7. https://doi.org/10.16348/j.cnki.cn61-1336/c.2019.04.001

Liu, G.W., Zhang, T.T., Yu, J., 2017. Research on the Relationship between Regional Synergy System of Innovation Network and Industrial Economic Growth. J. China Sci. Technol. Forum 123-132. https://doi.org/10.13580/j.cnki.fstc.2017.11.015

Liu, H.D., Chen, L., 2020. The Measurement of Regional Collaborative Innovation Efficiency and Its Key Influencing Factors_ B Based on Empirical Analysis of Static and Dynamic Spatial Panels. J. Sci. Technol. Manag. Res. 40, 55-63. https://doi.org/10.3969/j.issn.1000-7695.2020.12.008

Lv, H.P., Chi, R.Y., Hua, X.Y., 2017. Collaborative spatial linkages of innovative resources and regional economic growth: an empirical analysis based on China's provincial data. J. Geog. 37, 1649-1658. https://doi.org/10.13249/j.cnki.sgs.2017.11.006

Lv, L.J., Kan, D.X., 2017. An Empirical Study on the Impact of Industry-University-Research Collaborative Innovation on Economic Growth — Take Jiangxi Province as an example. J. Sci. Technol. Manag. Res. 37, 130-135. https://doi.org/10.3969/j.issn.1000-7695.2017.23.019

Persaud, A., 2005. Enhancing Synergistic Innovative Capability in Multinational Corporations: An Empirical Investigation. J. Prod. Innov. Manag. 22. https://doi.org/10.1111/j.1540-5885.2005.00138.x

Ren, B.P., Gan, H.X., 2016. The Construction of the Micro Mechanism for the Improvement of China's Economic Growth Quality. J. Guizhou Soc. Sci. 111-118. https://doi.org/10.13713/j.cnki.cssci.2016.05.019 
Wang, H., Cui, H., Zhao, Q., 2020. Effect of green technology innovation on green total factor productivity in China: Evidence from spatial durbin model analysis. J. Clean. Prod. 288, 125624. https://doi.org/10.1016/j.jclepro.2020.125624

Wang, W.J., Wei, H.A., 2016. Construction of the Evaluation Index System of Collaborative Innovation Capability — Based on the Empirical Research of the State Key Laboratory. J. Stud. Sci. Sci. 34, 471480. https://doi.org/10.16192/j.cnki.1003-2053.2016.03.018

Wang, X., Gao, S., 2018. Contribution rate of collaborative innovation and technological progress to the economic growth of the construction industry in the three eastern provinces. J. Technol. Ind. 18, 44-47. https://doi.org/CNKI:SUN:CYYK.0.2018-05-008

Wu, W.H., Li, N.N., Zhang, A.M., Liu, A.G., Wang, J.Y., 2016. The impact of the similarity, coupling and multidimensional proximity of innovation capabilities between Beijing-Tianjin-Hebei provinces and cities on collaborative innovation. J. Technol. Prog. Countermeas. 33, 24-29. https://doi.org/10.6049/kjjbydc.2015100448

Yang, Y.Z., Li, S., 2019. Research on the Evaluation of Cooperative Innovation of Industry-University-Research Institute Based on Factor Analysis. J. Math. Pract. Knowl. 49, 23-30. https://doi.org/CNKI:SUN:SSJS.0.2019-03-003

Zhang, J., Wu, G.Y., Zhang, J.P., 2004. China's inter-provincial material capital stock estimation: 1952-2000. J.

Zhao, Y.L., Chen, H.Z., 2020. Heterogeneous technological innovation and green total factor productivity

683

684

685

686

687

688

689

690

691

692

693

694

695

696

697
Zhao, Z., 2020. Connotation interpretation, interactive relationship and motivation mechanism of the coordinated development of universities and strategic emerging industries. J. High. Educ. Manag. 14, 9-18. https://doi.org/10.13316/j.cnki.jhem.20200507.002

Zhong, H.B., Liu, X., 2018. Arbitrage Entrepreneurship, Innovative Entrepreneurship and China's Economic Growth - Empirical Research Based on the Synergy of Marketization. J. Technol. Prog. Countermeas. 35, 74-81. https://doi.org/10.6049/kjjbydc.2017110354

Zhou, X.L., Li, T., 2017. Research on the Conditions of Promoting Economic Growth under the Co-evolution of Technological Innovation and Institutional Innovation. J. Southeast Acad. 189-197+248. https://doi.org/10.13658/j.cnki.sar.2017.01.021

Zhu, P.H., Li, J.L., 2019. How Fiscal Policy Affects Total Factor Productivity: A Perspective of Heterogeneity and Marketization. J. Shandong Univ. Soc. Sci. 85-95. https://doi.org/10.3969/j.issn.1001-9839.2019.01.010

Zhu, W.T., Lv, C.R., Gu, N.H., 2019. Research on the Impact of OFDI and Reverse Technology Spillover on Green Total Factor Productivity. J. China Popul. Environ. 29, 63-73. https://doi.org/10.12062/cpre.20181106 


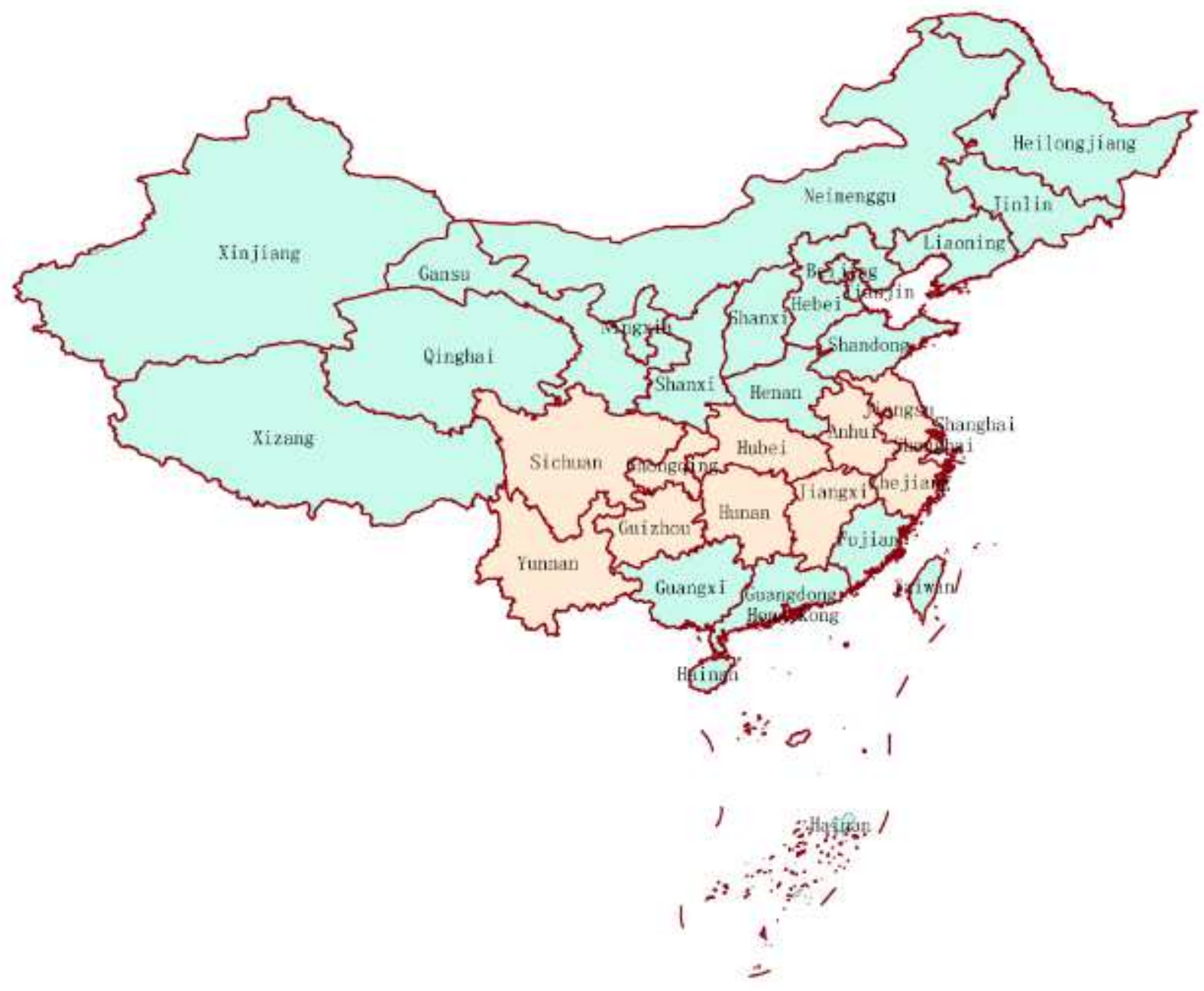

\section{Figure 1}

Map of the Yangtze River Economic Belt. Note: The designations employed and the presentation of the material on this map do not imply the expression of any opinion whatsoever on the part of Research Square concerning the legal status of any country, territory, city or area o bbnhjr of its authorities, or concerning the delimitation of its frontiers or boundaries. This map has been provided by the authors. 

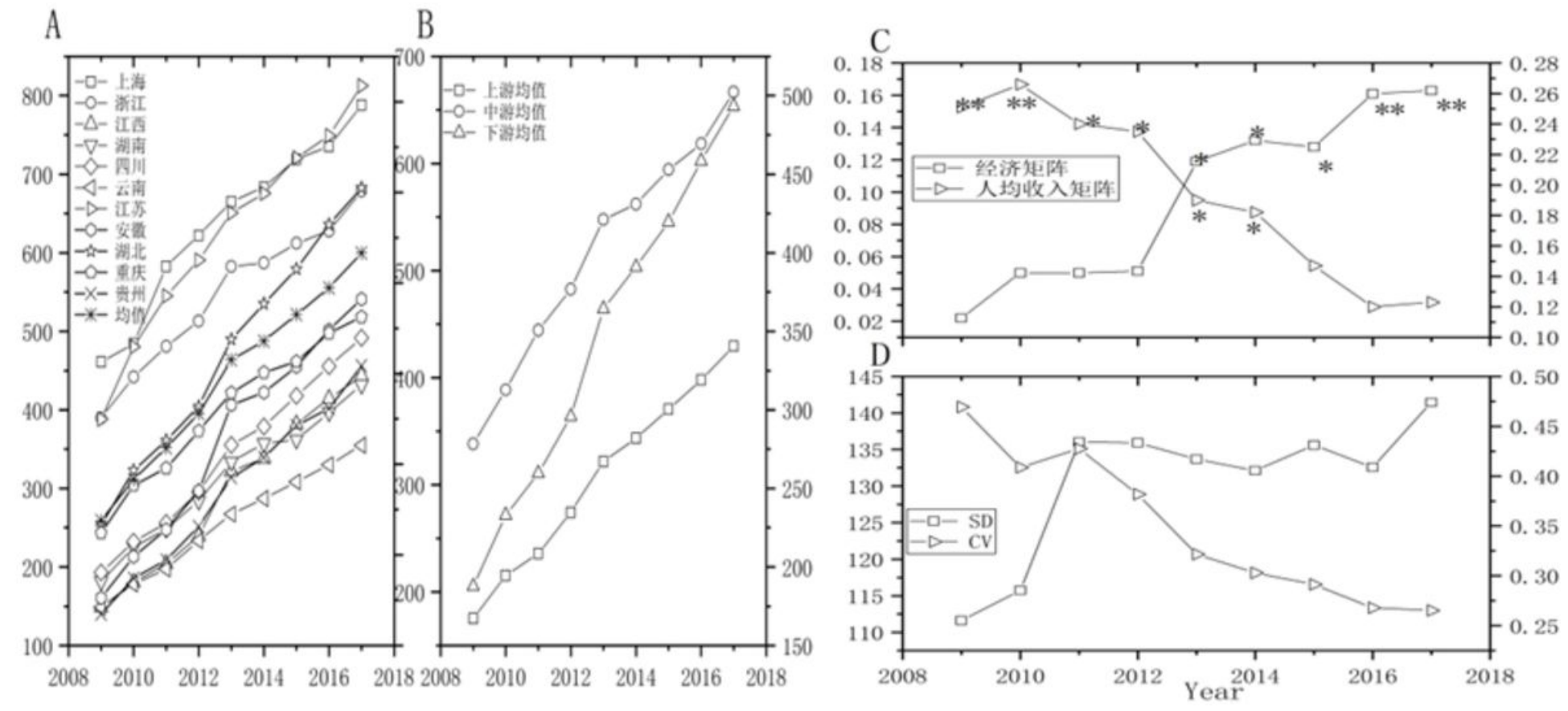

Figure 2

Changes in the level of collaborative innovation of provinces in the Yangtze River Economic Belt Note: A. The level and mean change of collaborative innovation in the provinces of the Yangtze River Economic Belt B. The mean change of regional collaborative innovation C. Moran 's I value of collaborative innovation corresponding to different matrices D. Standard deviation and coefficient of variation of collaborative innovation

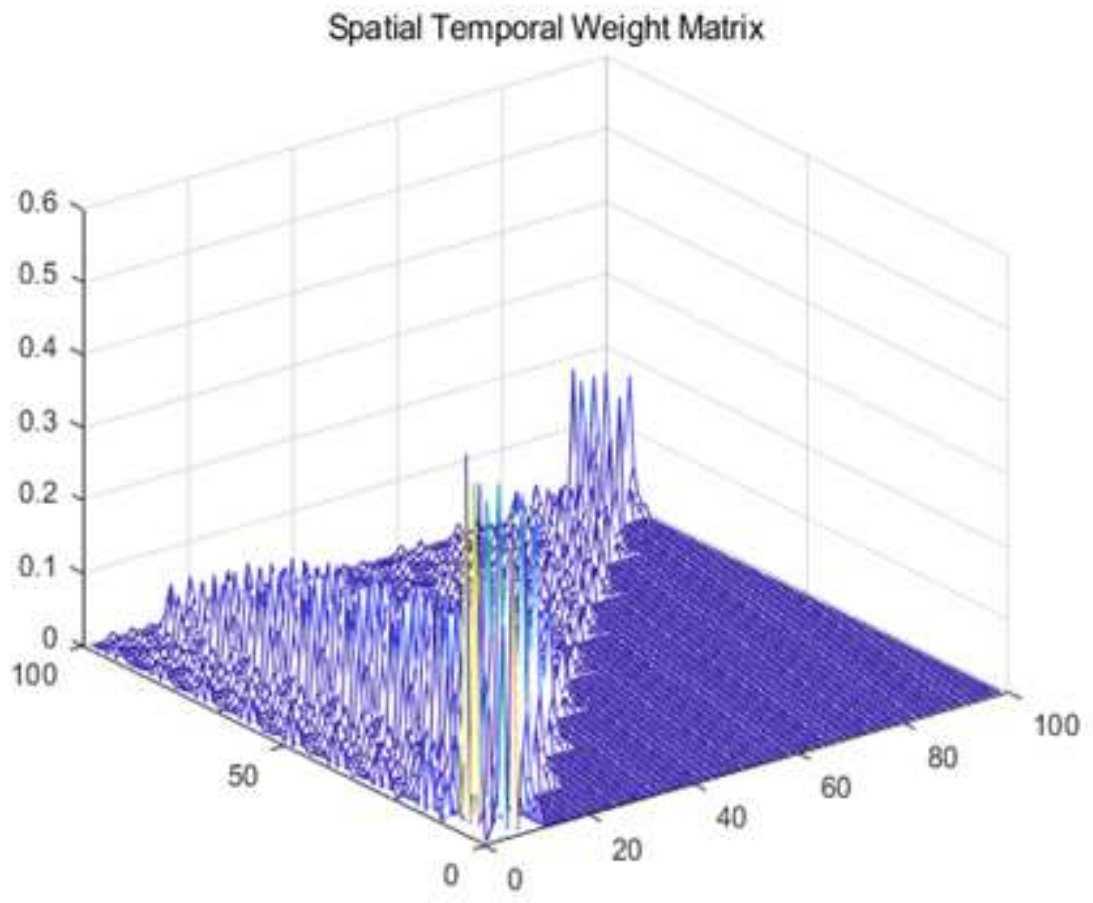

Figure 3 
Endogenous space-time weight matrix based on economic matrix

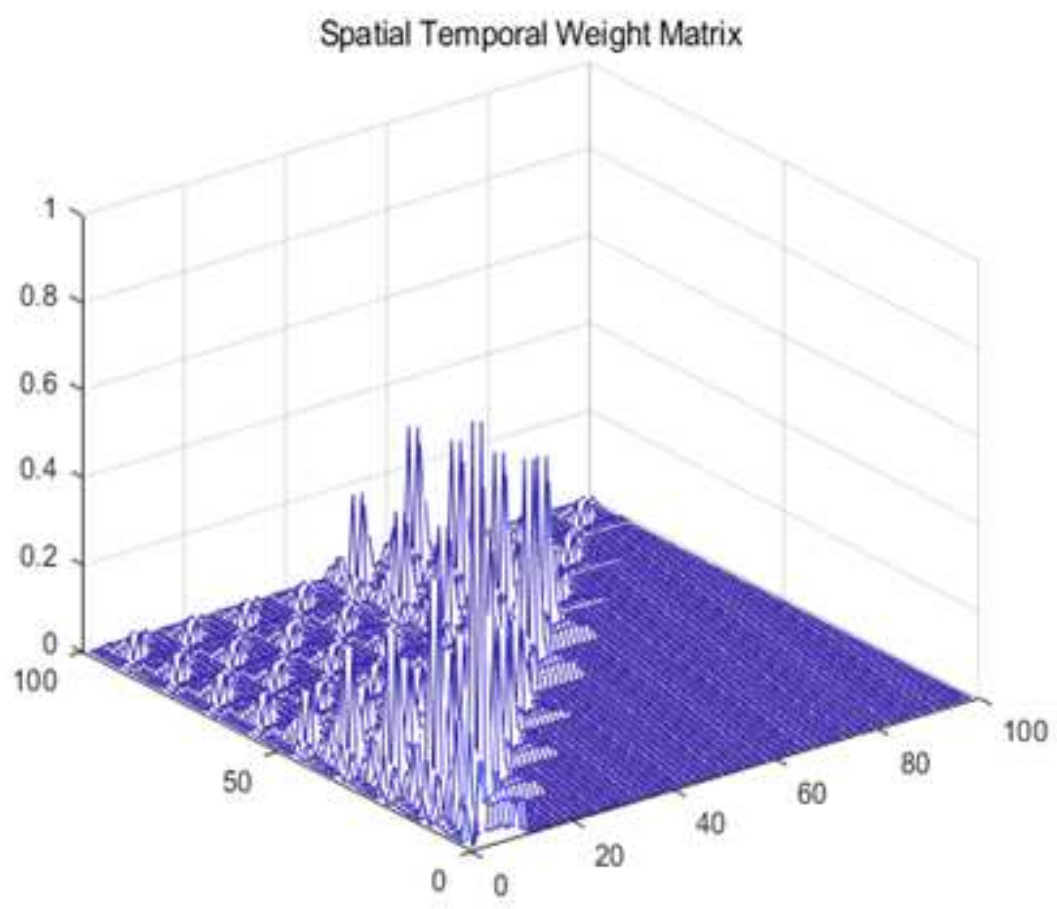

Figure 4

Endogenous time-space weight matrix based on per capita income matrix

\section{Supplementary Files}

This is a list of supplementary files associated with this preprint. Click to download.

- SupplementaryInformation.docx 